ARTICLE

DOI: $10.1038 / s 41467-018-06709-w$

\title{
Multifunctional molecular modulators for perovskite solar cells with over $20 \%$ efficiency and high operational stability
}

\author{
Dongqin Bi ${ }^{1}$, Xiong $\mathrm{Li}^{1,2}$, Jovana V. Milić (iD ${ }^{1}$, Dominik J. Kubicki ${ }^{1,3}$, Norman Pellet', Jingshan Luo (i) ${ }^{1,4}$ \\ Thomas LaGrange ${ }^{5}$, Pierre Mettraux ${ }^{6}$, Lyndon Emsley ${ }^{3}$, Shaik M. Zakeeruddin ${ }^{1} \&$ Michael Grätzel ${ }^{1}$
}

Perovskite solar cells present one of the most prominent photovoltaic technologies, yet their stability, scalability, and engineering at the molecular level remain challenging. We demonstrate a concept of multifunctional molecular modulation of scalable and operationally stable perovskite solar cells that exhibit exceptional solar-to-electric power conversion efficiencies. The judiciously designed bifunctional molecular modulator SN links the mercapto-tetrazolium $(\mathrm{S})$ and phenylammonium $(\mathrm{N})$ moieties, which passivate the surface defects, while displaying a structure-directing function through interaction with the perovskite that induces the formation of large grain crystals of high electronic quality of the most thermally stable formamidinium cesium mixed lead iodide perovskite formulation. As a result, we achieve greatly enhanced solar cell performance with efficiencies exceeding $20 \%$ for active device areas above $1 \mathrm{~cm}^{2}$ without the use of antisolvents, accompanied by outstanding operational stability under ambient conditions.

\footnotetext{
${ }^{1}$ Laboratory for Photonics and Interfaces, Ecole polytechnique fédérale de Lausanne, $\mathrm{CH}-1015$ Lausanne, Switzerland. ${ }^{2}$ Michael Grätzel Center for Mesoscopic Solar Cells, Wuhan National Laboratory for Optoelectronics, Huazhong University of Science and Technology, Wuhan 430074 Hubei, China.

${ }^{3}$ Laboratory for Magnetic Resonance, Ecole polytechnique fédérale de Lausanne, CH-1015 Lausanne, Switzerland. ${ }^{4}$ Institute of Photoelectronic Thin Film Devices and Technology, College of Electronic Information and Optical Engineering, Nankai University, 300350 Tianjin, China. ${ }^{5}$ Interdisciplinary Centre for Electron Microscopy, CH-1015 Lausanne, Switzerland. ${ }^{6}$ Molecular and Hybrid Materials Characterization Center, CH-1015 Lausanne, Switzerland. These authors contributed equally: Dongqin $\mathrm{Bi}$, Xiong Li. Correspondence and requests for materials should be addressed to

J.V.Mć. (email: jovana.milic@epfl.ch) or to M.Gät. (email: michael.graetzel@epfl.ch)
} 
ybrid organic-inorganic perovskite solar cells (PSCs) have attracted extensive research interest as the most rapidly developing next-generation thin-film photovoltaic technology due to their high solar-to-electric power conversion efficiency (PCE) and inexpensive fabrication ${ }^{1-4}$. The best performing PSCs have reached a PCE of $22.7 \%$ using the current state-of-theart mixed-cation MA/FA (methylammonium (MA), formamidinium (FA)) formulations ${ }^{5-7}$. However, these archetypical FA-based PSCs still contain MA cations rendering them prone to rapid thermal and moisture-induced degradation ${ }^{8,9}$. Furthermore, anti-solvents are required during the deposition of the perovskite film by spin coating to achieve top performance, which hampers the scaling of PSCs from laboratory cell to module size. In addition, recombination of charge carriers in currently employed PSCs occurs overwhelmingly via non-radiative recombination ${ }^{10,11}$. Crystal defects, in particular anion vacancies and coordinatively unsaturated lead cations that are located mostly at the grain boundaries (GBs) and at the interfaces with the charge carrier extraction layers, can lead to the formation of localized energy states in the band gap that enhance charge carrier recombination, ion migration, and moisture/oxygen permeation, which decreases the device performance and stability ${ }^{12}$. In this regard, strong adhesion of the electron and hole specific contacts to the perovskite film is essential to achieve top cell performance and high device stability. Any voids and pinholes generated during cell fabrication or during long term aging at the interface between the perovskite and the hole transport material (HTM), as well as the delamination of the HTM from the perovskite layer, will jeopardize the collection of photo-generated charge carriers and accelerate the perovskite decomposition by directly exposing it to the ambient atmosphere ${ }^{13}$.

These factors serve as a guideline for the design of perovskite materials and molecular engineering of additives that assist in increasing the grain size and passivating defects at the GBs and the interface with the electron and hole specific contacts, while strengthening the contact adhesion, in particular at the perovskite/HTM interface. However, only a few PSCs studies focus on the aforementioned factors so far. In the case of $\mathrm{MAPbX}_{3}$ and $\mathrm{FA}_{\mathrm{x}} \mathrm{MA}_{1-\mathrm{x}} \mathrm{PbX}_{3}$ perovskite formulations $(\mathrm{X}=\mathrm{I}, \mathrm{Br}$ ), attempts to passivate defects comprise treatment by different additives, such as $\mathrm{Cl}^{-}$ions ${ }^{14}, \mathrm{Cu}$ (thiourea) $\mathrm{I}^{15}$, thiocyanate ${ }^{16}$, or ammonium cations $^{17}$. Other approaches use thiols ${ }^{18}$, insulating polymers ${ }^{19}$, ammonium cations $17,20-22$, and alkylalkoxysilane $e^{23}$ to improve the moisture tolerance of the PSC. Despite the utility of such agents in passivating the defects and interfaces, the degradation of MA under light and elevated temperature limits the intrinsic stability of the MA-based perovskites. Hence, recent research focuses on the stable $\mathrm{FA}_{\mathrm{x}} \mathrm{Cs}_{1-\mathrm{x}} \mathrm{PbX}_{3}$ perovskite formulations ${ }^{24-26}$. However, the PCE of FA/Cs mixed-cation perovskite formulations remained until now below $18 \%$, even in the presence of additives such as $\mathrm{Pb}(\mathrm{SCN})_{2}$, which increases the perovskite grain size ${ }^{27}$, or blocking layers that improve the interface compatibility ${ }^{28}$. This "glass ceiling" is caused by a combination of several factors, namely small grain size, high density of surface defects, and roughness at the interfaces resulting from the fast crystallization of $\mathrm{FA}_{\mathrm{x}} \mathrm{Cs}_{1-\mathrm{x}} \mathrm{PbI}_{3}$. Therefore, in order to obtain higher $\mathrm{PV}$ performance of the robust FA/Cs perovskites, it is imperative to simultaneously improve film morphology and crystal quality, while enhancing the adhesion of the perovskite to the electron and hole specific contact materials. Towards this goal, molecular design of multifunctional agents that modulate the perovskite structure and performance is required.

Herein, we employ the most stable known perovskite formulation, $\mathrm{FA}_{0.9} \mathrm{Cs}_{0.1} \mathrm{PbI}_{3}$, as a light harvester and demonstrate a molecular design strategy to improve its electronic properties and photovoltaic performance, as well as strengthen the interaction of the perovskite with the electron and hole selective contacts to ascertain rapid charge carrier extraction during the service life. Towards this goal, our design reveals three prospective molecular modulators (MMs, Fig. 1), including thiol-based 5-(methylthio)$1 H$-tetrazole $(\mathrm{S})$, ammonium-based anilinium iodide $(\mathrm{N})$, and bifunctional 3-(5-mercapto-1H-tetrazol-1-yl)benzenaminium iodide (SN), which feature hydrophobic (hetero)aromatic cores functionalized by ammonium and thiol groups that can interact with specific components of the perovskite phase and ensure abatement of the defects. We found that ammonium-group $\left(-\mathrm{NH}_{3}{ }^{+}\right)$-containing modulator $\mathrm{N}$ effectively mitigates the A cation vacancy type lattice defects, while the thiol-functionalized $(-\mathrm{SH})$ modulator $\mathrm{S}$ is efficient in increasing the grain size and passivating coordinatively unsaturated $\mathrm{Pb}$ (II) ions on the surface. Based on these remarkable properties, we designed a bifunctional molecular modulator that combines the advantages of $\mathrm{S}$ and $\mathrm{N}$, namely SN, and adopts a unique tautomeric form upon linking the two functionalities, which exposes an additional hydrogenbond-donating site $(-\mathrm{NH})$ for interaction with the perovskite surface (Fig. 1). As a result, molecular modulation simultaneously enhances the perovskite grain size and crystallinity and reduces the level of defects acting as centers for nonradiative charge carrier recombination. By using this strategy, we achieve a PCE of over $20 \%$ for cells based on the $(\mathrm{FAI})_{0.9} \mathrm{Cs}_{0.1}\left(\mathrm{PbI}_{2}\right)_{1.05}$ composition with device active areas above $1 \mathrm{~cm}^{2}$, showing excellent operational stability. This approach unveils a generation of multifunctional molecular modulators (MMMs) with the capacity to advance PSC research and practical applications.

\section{Results}

Material characteristics of molecularly modulated perovskites. The perovskite films were fabricated via the vacuum-flashassisted anti-solvent-free solution processing (VASP) method ${ }^{29}$ The perovskite precursor solution of the $(\mathrm{FAI})_{0.9} \mathrm{Cs}_{0.1}\left(\mathrm{PbI}_{2}\right)_{1.05}$ composition, comprising $\mathrm{FA}_{0.9} \mathrm{Cs}_{0.1} \mathrm{PbI}_{3}$ with $5 \mathrm{~mol} \%$ excess $\mathrm{PbI}_{2}$, was first spin-coated on top of a mesoporous $\mathrm{TiO}_{2}$ film, followed by brief vacuum treatment to remove the volatile DMF solvent and boost rapid crystallization of the intermediate phase before annealing at $100{ }^{\circ} \mathrm{C}$ for $60 \mathrm{~min}$. The S, N, and SN modulators were added into the perovskite precursor solution at molar ratio of $2 \mathrm{~mol} \%$ with respect to $\mathrm{PbI}_{2}$. In addition, a passivation layer was deposited by spin-coating a solution of $0.5 \mathrm{mg} / \mathrm{mL} \mathrm{S}, \mathrm{N}$, and $\mathrm{SN}$ additives in isopropanol onto the annealed perovskite films, followed by a second annealing step for $10 \mathrm{~min}$ at $70^{\circ} \mathrm{C}$. After cooling down, the hole transporting layer (HTL), i.e. $2,2^{\prime}, 7,7^{\prime}$ tetrakis( $N, N$-di-pmethoxyphenylamine)-9,9-spirobifluorene

(spiro-OMeTAD), containing tert-butyl-pyridine $(t$-BP) and lithium bis(trifluoromethylsulphonyl)imide (LiTFSI) was spincoated onto the perovskite film. Finally, a $80 \mathrm{~nm}$ gold layer was evaporated onto HTL to complete the device. Further details of device fabrication are provided in the Methods.

The effect of the molecular modulators on the morphology of the films was probed by scanning electron microscopy (SEM; Fig. 1a). Plane-view SEM images reveal that the perovskite grain size is about $300 \mathrm{~nm}$ in the control film, while it increases up to 1 $\mu \mathrm{m}$ for the films containing either modulator S or SN. Moreover, additional bright nanoplates were observed within the perovskite grain boundaries, as shown by the cross-sectional SEM (Fig. 1a, bottom). Their number was reduced in the presence of modulators $\mathrm{S}$ and $\mathrm{N}$, while they completely disappear upon SN treatment. In fact, the effective grain boundary area decreased upon addition of $\mathrm{S}$ and $\mathrm{SN}$, accompanied by preferred perpendicular orientation of the boundaries with respect to the substrate, which is known to minimize the overall grain boundary energy $^{30}$. Consequently, very few grain boundaries are visible 
a
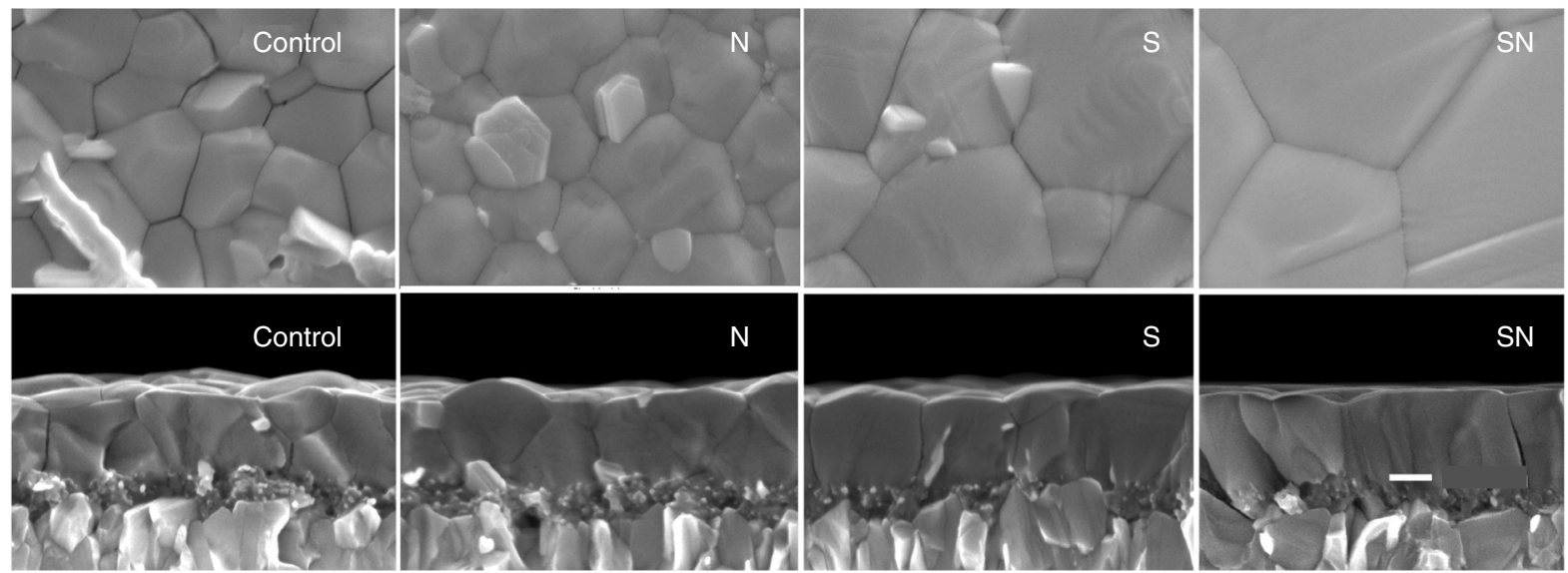

b
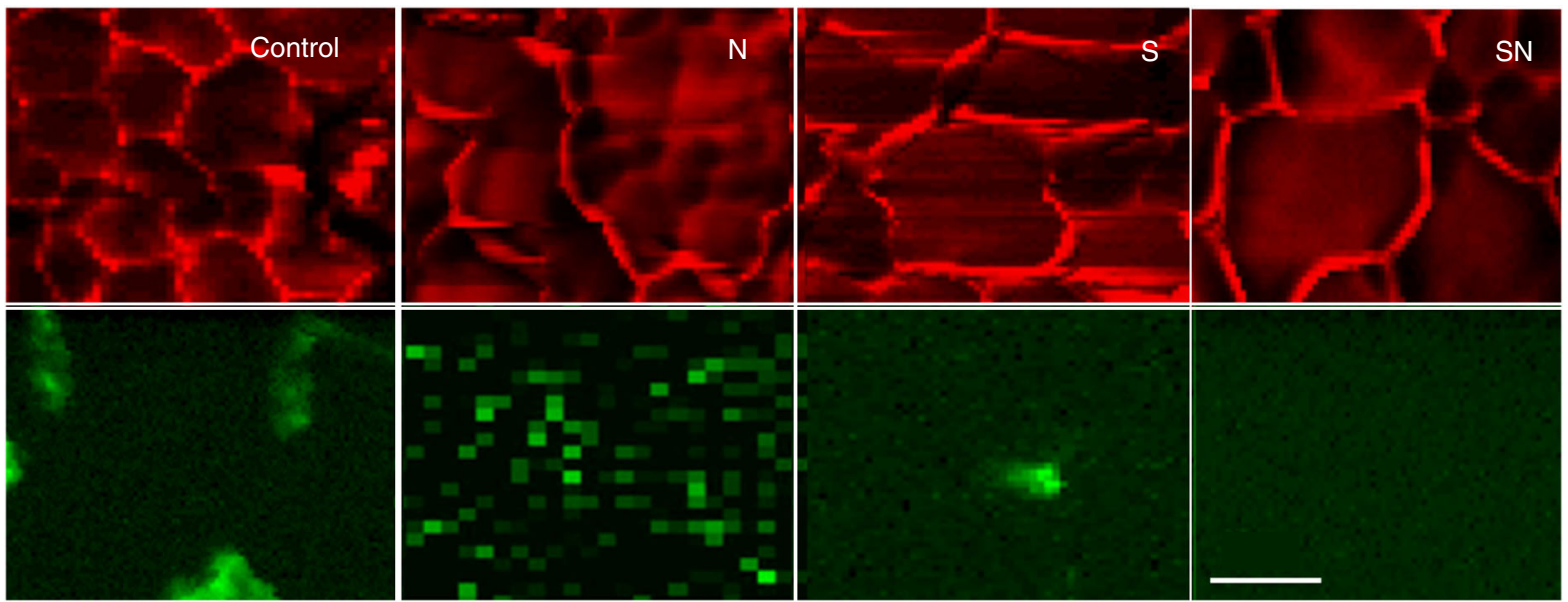

$\mathbf{C}$

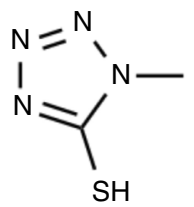

S

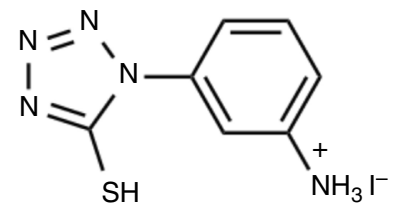

$\mathrm{SH}$

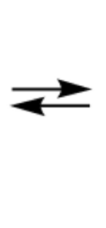

SN
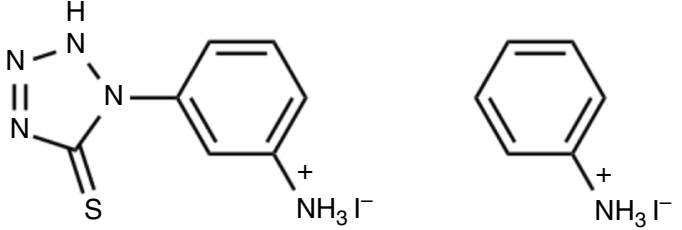

$\mathbf{N}$

Fig. 1 Structural characterization of modulated perovskite films. a Plane-view (top) and cross-sectional (bottom) SEM images of the pristine (control) and modulator-containing ( $\mathrm{N}, \mathrm{S}$, and SN) perovskite films deposited on the mesoporous- $\mathrm{TiO}_{2} /$ compact- $\mathrm{TiO}_{2} / \mathrm{FTO}$. Scale bar represents $200 \mathrm{~nm}$.

b Cathodoluminescence $(\mathrm{CL})$ mapping of the pristine (control) and additive-containing (N, S, and SN) perovskite films deposited on the ITO (1 mm) glass substrates. The spatial distribution of green and red light emission, recorded from 530 to $590 \mathrm{~nm}$ and from 700 to $800 \mathrm{~nm}$, respectively, reveals the microscopic distribution of $\mathrm{Pbl}_{2}$ phase in the perovskite films. Scale bar represents $1 \mu \mathrm{m}$. c Structure of N, S, and SN modulators employed in the study, with the corresponding tautomeric forms of SN (the geometries optimized by DFT calculations at B3LYP/6-31 G(d) level of theory are provided in Supplementary Figure 1, whereas the corresponding NMR spectra are shown in Supplementary Figures 2-5 that reveal the predominance of the thione tautomeric form and the interaction with the perovskite and $\mathrm{Pbl}_{2}$ phase). ITO: indium tin oxide, FTO: fluorine-doped tin oxide

within the plane of the capping layer, suggesting lower density of defects. This is expected to reduce the defect-driven non-radiative charge carrier recombination, enhancing the open circuit voltage ( $\left.V_{\text {OC }}\right)$ of the cells ${ }^{4}$.

Having demonstrated the large beneficial effect of the additives on the perovskite film morphology, their effect on the phase segregation between the perovskite and $\mathrm{PbI}_{2}$ components was further evaluated via cathodoluminescence $(\mathrm{CL})$ mapping of the perovskite deposited on a thin $(1.1 \mathrm{~mm})$ ITO-coated glass substrates. Before CL characterization, the perovskite films were kept inside a vacuum chamber overnight in the dark, to avoid unintended light-induced degradation. Furthermore, the CL mappings were recorded from regions of the sample that were previously unexposed, except when specifically indicated. The CL maps are shown in Fig. 1b, and the color is divided into green and red regions by using different spectral windows from 530 to 590 $\mathrm{nm}$ and from 700 to $800 \mathrm{~nm}$, respectively. This study revealed substantial amount of $\mathrm{PbI}_{2}$ crystallites located randomly in the control and modulator $\mathrm{N}$-containing perovskite films, while the amount of $\mathrm{PbI}_{2}$ was found to decrease in the modulator 

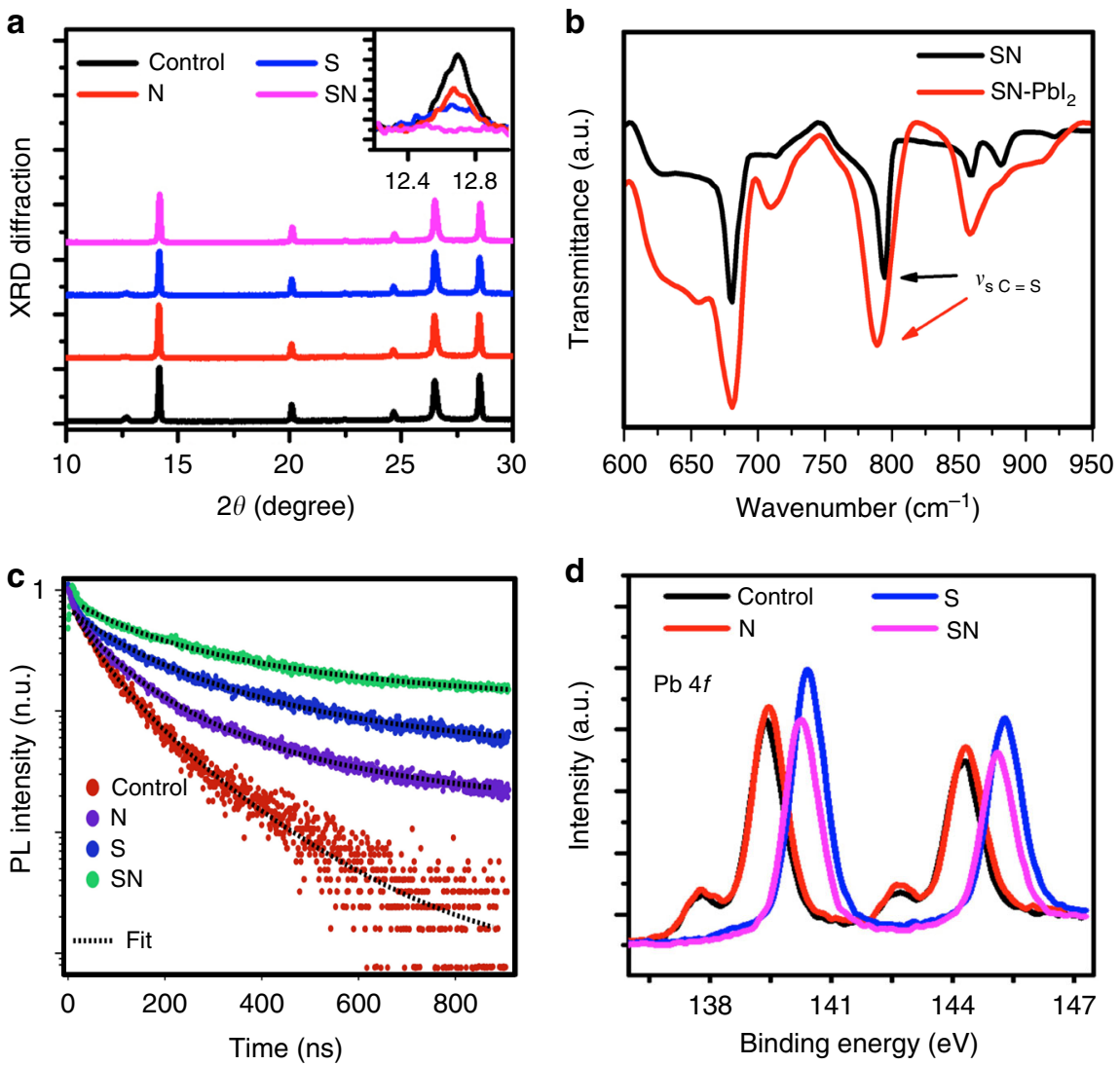

Fig. 2 Material characterization of perovskite films. a XRD patterns. A peak at $12.5^{\circ}$ that arises from the (001) lattice planes of hexagonal ( $2 \mathrm{H}$ polytype) $\mathrm{Pbl}_{2}$ is shown in the inset. b Fourier transform infrared (FTIR) spectra. c Time-resolved photoluminescence measurements of the pristine (control) and modulator-containing (N, S, and SN) perovskite films. The arrows in $\mathbf{b}$ indicate the stretching vibration peak of $\mathrm{C}=\mathrm{S}$ in the films, and the dashed lines in c show the fits of the experimental data to Eq. (3). $\mathbf{d}$ X-ray photoelectron spectroscopy of the perovskite films in the absence (control) and presence of molecular modulators (N, S, and SN). The binding energies at approximately $138 \mathrm{eV}$ and $142.5 \mathrm{eV}$ in $\mathbf{d}$ denote the signals for Pb(II) species resulting from interfacial decomposition, such as $\mathrm{PbO}$, whereas the predominant $\mathrm{Pb} 4 f$ signals can be ascribed to unsaturated $\mathrm{Pb}^{2+}$ surface ions ${ }^{35,36}$

S-containing perovskite film and vanish in the sample with SN. The disappearance of $\mathrm{PbI}_{2}$ in the $\mathrm{CL}$ maps could be explained either by its absence in the treated films or by its amorphization. This is in accordance with the propensity of crystalline metal halides to demonstrate stronger luminescence when compared with their amorphous counterparts ${ }^{31}$. We confirmed the disappearance of the crystalline $\mathrm{PbI}_{2}$ phase by X-ray diffraction (XRD) measurements carried out on the thin films (Fig. 2a), which was further assessed by solid-sate NMR spectroscopy discussed below.

Diffractograms of all the samples, except for those treated with $\mathrm{SN}$, show a peak at $12.5^{\circ}$, which arises from the (001) lattice planes of hexagonal (2H polytype) $\mathrm{PbI}_{2}$ (Fig. 2b, inset). Moreover, they all show the same trigonal perovskite phase with the dominant (111) lattice reflection of $2 \theta$ at $14.15^{\circ}$. By taking the full-width-at-half-maximum (FWHM) of the (111) reflection, we calculate the crystallite size using Scherrer's equation. Accordingly, the dimension increases from $61 \mathrm{~nm}$ for the control sample to 89,118 , and $140 \mathrm{~nm}$ in the case of the modulator N, S, and SN containing samples, respectively. These results indicate that all three additives can simultaneously increase perovskite crystallinity and the grain size, with the bifunctional SN producing the most significant improvements. We rationalize this effect in terms of the retarded crystallization due to the Lewis acid-base interaction between the sulfur ( $\mathrm{S}$ ) donor group and $\mathrm{Pb}^{2+}$, which was probed by Fourier transform infrared spectroscopy (FTIR). The FTIR spectra revealed a red-shift of the $\mathrm{C}=\mathrm{S}$ vibration from $794 \mathrm{~cm}^{-1}$ in pure $\mathrm{SN}$ to $788 \mathrm{~cm}^{-1}$ upon interaction with $\mathrm{PbI}_{2}$
(Fig. 2b), indicating the formation of an intermediate $\mathrm{SN}-\mathrm{PbI}_{2}$ adduct weakening the $\mathrm{C}=\mathrm{S}$ bond strength caused by the interaction with the $\mathrm{PbI}_{2}$ as a Lewis acid. XRD patterns, however, do not reveal formation of any new phases, despite the usage of $5 \%$ excess of $\mathrm{PbI}_{2}$ in the preparation of all the films. This further suggests that the luminescence decrease in the CL measurements is in accordance with $\mathrm{PbI}_{2}$ either becoming amorphous and undetectable upon addition of $\mathrm{SN}$, presumably due to the intercalation of the modulator into the layered $\mathrm{PbI}_{2}$ lattice resulting in the formation of an amorphous form or potentially a $2 \mathrm{D}$ perovskite structure, which is a subject of our ongoing investigation.

Investigation of the origin of molecular modulation. In order to shed light on the microscopic interaction between SN and the perovskite lattice, we carried out solid-state NMR experiments using $\mathrm{a}-\mathrm{FAPbI}_{3}$ as a model perovskite compound (Fig. 3, for more details refer to the Methods and Supplementary notes). The nitrogen-14 magic angle spinning (MAS) NMR spectra of bulk mechanochemical $\alpha-\mathrm{FAPbI}_{3}$ (Fig. 3a) and bulk mechanochemical a-FAPbI ${ }_{3}$ doped with $4 \mathrm{~mol} \% \mathrm{SN}$ (Fig. $3 \mathrm{~b}$ ) feature a ${ }^{14} \mathrm{~N}$ spinning sideband (SSB) pattern that is noticeably narrower in the material treated with SN compared to the untreated reference. We have previously shown that the breadth of the residual ${ }^{14} \mathrm{~N}$ SSB manifolds is affected by the reorientation of FA in the fast motion regime with correlation times on the order of picoseconds, and it is related to the symmetry of cation reorientation inside the cuboctahedral perovskite cavity ${ }^{32,33}$. In this regard, narrower ${ }^{14} \mathrm{~N}$ 

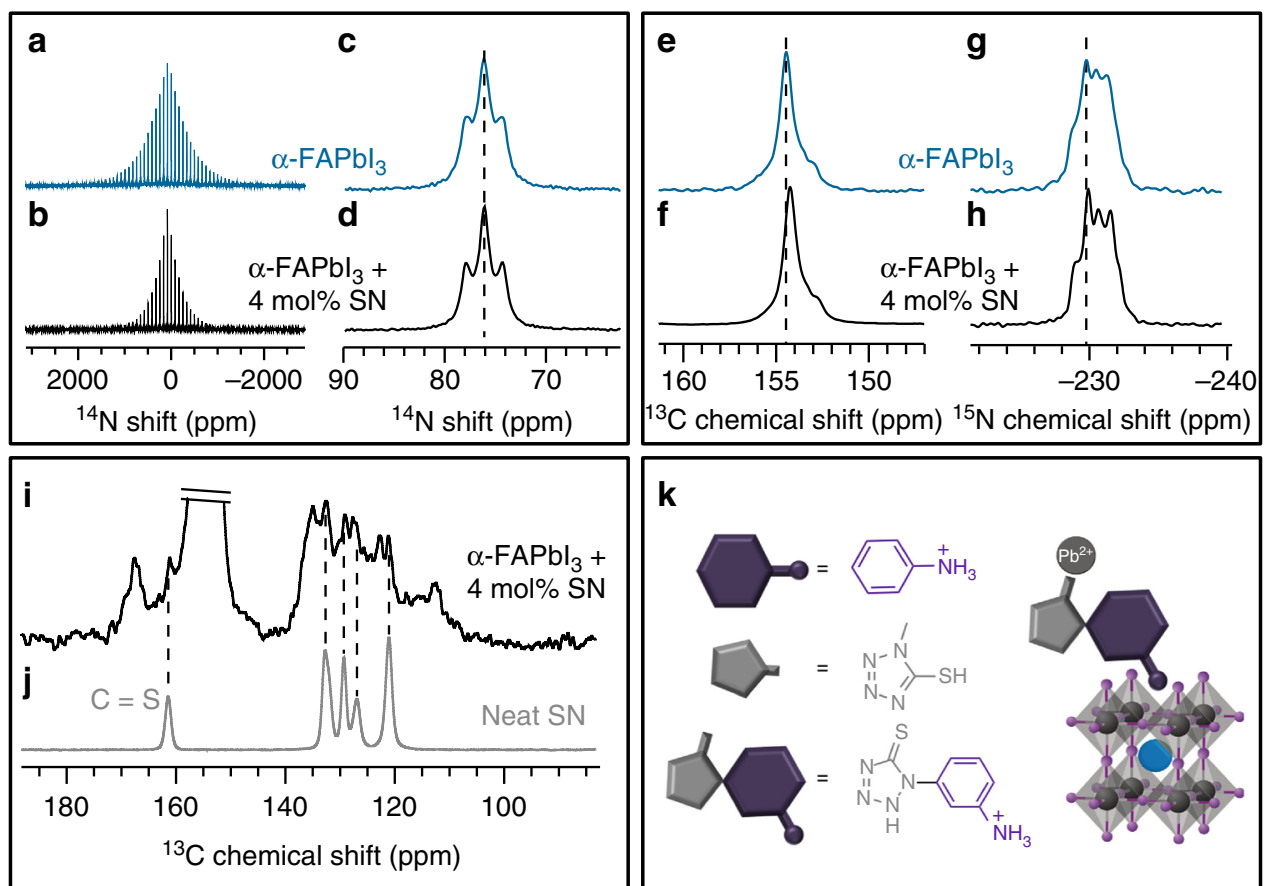

Fig. 3 Investigation of the origin of perovskite modulation by NMR spectroscopy. a-d ${ }^{14} \mathrm{~N}$ solid-state MAS NMR spectra at $11.7 \mathrm{~T}, 298 \mathrm{~K}$ and $\mathbf{a}, \mathbf{b} 3 \mathrm{kHz}$, c, $\mathbf{d}, 20 \mathrm{kHz}$ MAS of bulk mechanochemical $\mathbf{a}, \alpha-\mathrm{FAPbl}_{3}$ and $\mathbf{b}, \alpha-\mathrm{FAPbl}_{3}$ doped with 4 mol\% SN. c, $\mathbf{d}$, shows the corresponding close-up views of the center band. The triplet is caused by the ${ }^{1} \mathrm{H}-{ }^{14} \mathrm{~N} \mathrm{~J}$-coupling. $\mathbf{e}-\mathbf{j},{ }^{13} \mathrm{C} \mathrm{CP}$ and ${ }^{15} \mathrm{~N} \mathrm{CP}$ solid-state MAS NMR spectra at $11.7 \mathrm{~T}, 105 \mathrm{~K}$ and $10 \mathrm{kHz}$ MAS of bulk mechanochemical e, $\mathbf{g} \alpha-\mathrm{FAPbl}_{3}$ and $\mathbf{f}, \mathbf{h} \alpha-\mathrm{FAPb}_{3}$ doped with 4 mol\% SN (intensity normalized to the peak of $\alpha-\mathrm{FAPbl}_{3}$ ). $\mathbf{i}, \mathbf{j}{ }^{13} \mathrm{C} \mathrm{CP}$ solid-state $\mathrm{MAS} \mathrm{NMR}$ spectra at $11.7 \mathrm{~T}, 105 \mathrm{~K}$, and $10 \mathrm{kHz}$ MAS of $\mathbf{i}$, bulk mechanochemical $\alpha$-FAPbl ${ }_{3}$ doped with 4 mol\% SN (scaled 64 times to highlight the SN resonances) and j neat SN powder. $\mathbf{k}$ Schematic representation of the structure of molecular modulators N (purple), S (gray), and SN (purple-gray), and the interaction of the bifunctional molecular modulator $\mathrm{SN}$ with $\mathrm{Pb}^{2+}$ ions (gray sphere) and perovskite crystal structure (general formula FAPbl ${ }_{3}$, where FA is represented by the central blue sphere, while $\mathrm{Pb}^{2+}$ and $\mathrm{I}^{-}$are shown as gray and bright purple spheres, respectively). MAS: magic angle spinning, $\mathrm{CP}$ : cross-polarization

SSB manifolds indicate higher symmetry that is closer to cubic. This suggests that the overall crystallographic symmetry of the $\alpha-$ $\mathrm{FAPbI}_{3}$ phase is affected by the presence of the $\mathrm{SN}$. However, the isotropic central peak has an identical shift in both materials, suggesting only a subtle extent of structural modification (Fig. 3c, d). The change in breadth of the FA ${ }^{14} \mathrm{~N}$ SSB manifold could potentially also be caused by incorporation of the $\mathrm{SN}$ cation into the $3 \mathrm{D}$ perovskite lattice, similarly to the behavior observed in mixed MA/FA, MA/GUA (GUA = guanidinium), and FA/GUA materials ${ }^{32,33}$. However, the largest cation which has been shown to transiently incorporate into the $\alpha-\mathrm{FAPbI}_{3}$ lattice is guanidinium ${ }^{33}$, which is substantially smaller than the SN cation, hence its incorporation into the $3 \mathrm{D}$ perovskite structure is unlikely. If it were to be incorporated, it would be expected to undergo reorientation on the picosecond timescale, similar to MA, FA, and GUA, and as a consequence yield similar motion-narrowed ${ }^{14} \mathrm{~N}$ spectra, with a peak intensity comparable to the third order SSB of $\alpha-\mathrm{FAPbI}_{3}$. The ${ }^{14} \mathrm{~N}$ spectrum of the treated material acquired over the period of $14 \mathrm{~h}$ shows no signs of any additional narrow SSB manifolds (see Supplementary Figure 3), which strongly suggests that the $\mathrm{SN}$ is rigid. This finding permits to conclude that the change in the crystallographic symmetry of the treated $\alpha$ $\mathrm{FAPb}_{3}$ phase is not caused by cation incorporation, but rather a surface interaction, suggesting that $\mathrm{SN}$ (stabilized in the thione tautomeric form as shown in the Supplementary Figure 4) may feature a structure-directing role, promoting growth of an altered perovskite structure compared to that of untreated $\alpha-\mathrm{FAPbI}_{3}$. Molecules directing the assembly pathways are widely used in the synthesis of mesoporous materials, such as zeolites and molecular sieves $^{34}$. This structure-direction role can occur through different modes of action, namely stabilization through hydrogen bonding of the donor groups $\left(-\mathrm{NH}_{3}{ }^{+},-\mathrm{NH}\right)$ to the perovskite surface and interaction with the $\mathrm{Pb}^{2+}$ ions via thione $(\mathrm{C}=\mathrm{S})$ coordination. While the first mode would only be characteristic for the perovskite, the latter is complementary to the interaction with the $\mathrm{PbI}_{2}$ phase (as detailed in Supplementary Figure 5).

To further probe the atomic-level interaction between $\mathrm{SN}$ and a-FAPbI 3 we acquired ${ }^{13} \mathrm{C}$ and ${ }^{15} \mathrm{~N}$ spectra of the treated and untreated material. The main perovskite phase in both cases yields very similar ${ }^{13} \mathrm{C}$ and ${ }^{15} \mathrm{~N}$ resonances (Fig. $3 \mathrm{e}-\mathrm{h}$, respectively), providing further evidence that $\mathrm{SN}$ does not incorporate into the perovskite lattice. There is, however, a small up-field shift of about $0.2 \mathrm{ppm}$ in both spectra upon SN treatment indicating the potential presence of small structural differences between the two materials. On the contrary, the SN resonances show clear differences between the SN-treated perovskite (Fig. 3i) and neat SN (Fig. 3j) acquired under otherwise identical experimental conditions. We observe two sets of additional peaks, one of which corresponds to the native $\mathrm{SN}$, while the other set appears compatible with $\mathrm{SN}$ in a new environment, e.g. in direct interaction with the perovskite. The aromatic carbon peaks are significantly shifted and broadened in the ranges between 110 and 120 as well as 135 and $140 \mathrm{ppm}$, and similarly, the $\mathrm{C}=\mathrm{S}$ carbon peak is shifted and broadened to the range between 165 and 170 $\mathrm{ppm}$. These new carbon environments can be ascribed to the SN interacting with the surface of the $\alpha-\mathrm{FAPbI}_{3}$ phase, in line with the structure-directing hypothesis. Accordingly, treatment of the perovskite material with $\mathrm{SN}$ tunes the morphology of the perovskite layer through its structure-directing function by binding to the perovskite surface (as schematically illustrated in Fig. 3k), which benefits both device performance and stability. 
The effect of the modulators on the charge carrier dynamics was further investigated by time-resolved photoluminescence (TRPL) decay measurements. We examined the temporal evolution of the photoluminescence (PL) emission at $790 \mathrm{~nm}$ using perovskite films containing modulators $\mathrm{N}, \mathrm{S}$, and $\mathrm{SN}$ that were spin-coated on a glass substrate, as presented in the time-resolved emission curve (Fig. 2c). Neglecting Auger-type recombination, we analyze the kinetics of the PL decay by the differential rate law:

$$
-\frac{\mathrm{d} n}{\mathrm{~d} t}=k_{1} n+k_{2} n^{2}
$$

where $k_{1}$ and $k_{2}$ are the pseudo-first and second order rate constants for non-radiative (trap controlled) and bimolecular radiative recombination of the photo-generated charge carriers, respectively, and $n$ is the charge carrier concentration respectively. Given that the perovskite is not doped showing only weak p-conduction in the pristine state, we assume that most charge carriers are photo-generated and hence the electrons and holes are present at equal concentration throughout the reaction $\left(n_{\mathrm{e}-}=\right.$ $\left.n_{\mathrm{h}+}=n\right)$. Integration of Eq. (1) yields Eq. (2) where $n^{0}$ and $n(t)$ denote the concentration of charge carriers immediately after laser excitation of the perovskite and at time $t$, respectively:

$$
n(t)=\frac{k_{1}}{k_{2}} \cdot \frac{1}{\mathrm{e}^{k_{1} t} \cdot\left(1+\frac{k_{1}}{n^{0} k_{2}}\right)-1}
$$

The temporal decay of the photoluminescence intensity $I_{\mathrm{PL}}(t)$ is shown in Fig. 2c, reflecting the number of photons emitted by the perovskite per unit time. As the photons are generated by bimolecular radiative recombination of charge carriers, their concentration $\left(n_{h v}\right)$ varies according to the differential rate law:

$$
I_{\mathrm{PL}}(t) \sim \frac{\mathrm{d} n_{h \nu}}{\mathrm{d} t}=k_{2} n^{2}=\frac{k_{1}^{2}}{k_{2}} \cdot \frac{1}{\left[\mathrm{e}^{k_{1} t} \cdot\left(1+\frac{k_{1}}{n^{0} k_{2}}\right)-1\right]^{2}}
$$

The dashed lines plotted in Fig. 2c reflect the decay kinetics described by Eq. (3). Their excellent fit with all four of the experimental curves validates the kinetic model we applied to interpret the PL data. From fitting of the luminescence decays in Fig. $2 c$ to Eq. (3), we derive the lifetimes $\tau_{1}$ as $1 / k_{1}$ (listed in Supplementary Table 1) for the first order non-radiative PL decay process. The SN-treated perovskite film clearly exhibits the longest lifetime, with the $\tau_{1}$ value of $2770 \mathrm{~ns}$ being exceptionally long for metal halide perovskites, exceeding that of the pristine film 7.3 times and being about twice as long as the N-containing sample. This indicates the dramatic effect exerted by the SN modulator on the passivation of defects in the crystal lattice and at interfaces and hence the improvement of electronic quality of the perovskite film.

We obtained further evidence for the reduced level of defects by X-ray photoelectron spectroscopy (XPS) analysis. We use the carbon $1 \mathrm{~s}$ line (for hydrocarbons or hydrocarbon-containing groups) to calibrate the binding-energy scale for all the XPS measurements and assume a binding energy of $284.8 \mathrm{eV}$ for this purpose (for details on the XPS spectra of perovskite films on mesoporous- $\mathrm{TiO}_{2} /$ compact- $\mathrm{TiO}_{2} / \mathrm{FTO}$ substrates, refer to the Supplementary Figure 6). The XPS spectra display similarities in the relative intensities of the core-level peaks (Fig. $2 \mathrm{~d}$ ). The $\mathrm{Pb} 4 f$ core level predominantly shows symmetric peaks with the $\mathrm{Pb} 4 f 7 / 2$ level at a binding energy of $139.5 \mathrm{eV}$ for the control sample and $\mathrm{N}$ containing perovskite, and $140.4 \mathrm{eV}$ for the modulators S and $\mathrm{SN}$ containing perovskites. This indicates a $0.9 \mathrm{eV}$ shift to higher binding energy upon addition of $\mathrm{S}$ or $\mathrm{SN}$ modulator into the perovskite films. Since X-rays penetrate only a few nanometers into perovskite film, XPS probes mainly the species present at its surface. Thus, we attribute the $\mathrm{Pb}$ signal at $139.5 \mathrm{eV}$ to coordinatively unsaturated $\mathrm{Pb}^{2+}$ surface ions and rationalize its shift to higher energy in terms of bond formation with the sulfur moieties of modulators SN or S, which is in line with the NMR studies (Fig. 3; for details see the Supplementary notes). The spin-orbit splitting between the $\mathrm{Pb} 4 f 7 / 2$ and $\mathrm{Pb} 4 f 5 / 2$ levels in all cases remains at 4.8 $\mathrm{eV}$, which is in accordance with literature values ${ }^{35}$. The $\mathrm{Pb} 4 f$ spectra also reveal a much smaller peak at $137.8 \mathrm{eV}$ and $142.6 \mathrm{eV}$ that can be attributed to other $\mathrm{Pb}$ (II) species by comparison with the known $\mathrm{Pb}$ binding energies, such as $\mathrm{PbO}$, which can form as a decomposition product at the interface ${ }^{36}$. This component is more apparent for the control and modulator $\mathrm{N}$-containing perovskite films, yet it is hardly noticeable in the modulator $\mathrm{S}$ and $\mathrm{SN}$ containing samples. We assume that the appearance of $\mathrm{Pb}(\mathrm{II})$ species might be related to the removal of iodine from the perovskite under formation of iodide vacancies in the lattice, as well as result from the exposure to the traces of oxygen and water in the environment. Such lead species are likely to act as non-radiative recombination centers reducing photovoltaic performance. Thus, elimination of the unsaturated lead content is critical to realizing perovskite films of high electronic quality ${ }^{23}$. As XPS data suggest that modulators $\mathrm{S}$ and $\mathrm{SN}$ greatly reduce the density of coordinatively unsaturated $\mathrm{Pb}^{2+}$ sites (Fig. 2d), these modulators are proven effective in passivating the surface defects of the perovskite films. The effect on the defects present in the deeper region of the film was probed by the XPS depth profile measurement (as presented in Supplementary Figure 7), which indicate that $\mathrm{Pb}$ (II) peak is greatly reduced in the films upon treatment with modulators $\mathrm{N}$ and $\mathrm{SN}$. A lower level of $\mathrm{Pb}(\mathrm{II})$ species indicate fewer iodide vacancies in the crystal lattice of the perovskite, as well as reduced interfacial decomposition, which in turn retards non-radiative recombination and increases the PL lifetime, in line with the TRPL results (shown in Fig. 2c). From this study, we can deduce that the bifunctional molecular modulator SN is effective in combining the traits of both modulators $\mathrm{S}$ and $\mathrm{N}$ in improving the quality of the perovskite films, while mitigating defects and stabilizing the perovskite interface.

Photovoltaic performance. In order to evaluate the effects of the modulators on the photovoltaic performance, we fabricated PCSs of the architecture $\mathrm{Au} /$ spiro-OMeTAD/perovskite/mesoporous- $\mathrm{TiO}_{2} /$ compact- $\mathrm{TiO}_{2} /$ FTO having an active area of $1.44 \mathrm{~cm}^{2}(12 \mathrm{~mm} \times 12$ $\mathrm{mm})$ and an aperture area of $1 \mathrm{~cm}^{2}$. PV metrics from 40 cells are presented in Fig. $4 \mathrm{a}$. The $J-V$ metrics of pristine perovskites, as well as the additive-containing perovskite layer-based PSCs obtained under standard AM $1.5 \mathrm{G}$ illumination at a light intensity of 100 $\mathrm{mW} \mathrm{cm}{ }^{-2}$, are shown in Fig. 5a. All three modulators increase $J_{\mathrm{SC}}$, $V_{\mathrm{OC}}$, and PCE and exhibit lower hysteresis than the control upon altering the scan direction (Fig. 4b). This was particularly the case for the samples treated with the SN modulator that achieved a PCE of $20.9 \%$ on forward scan at $1 \mathrm{~cm}^{2}$ mask aperture area, the total device area being $1.44 \mathrm{~cm}^{2}$. The photovoltaic metrics of the corresponding device are as follows: short-circuit current density $\left(J_{\mathrm{SC}}\right)$ is $24.0 \mathrm{~mA} \mathrm{~cm}^{-2}$, open circuit voltage $\left(V_{\mathrm{OC}}\right)$ is $1.15 \mathrm{~V}$, and fill factor (FF) is 0.75 . The larger $V_{\mathrm{OC}}$ originates from suppression of charge carrier recombination due to defect passivation in accordance with the PL and XPS measurements. We attribute the small increase in $J_{\mathrm{SC}}$ to better collection of charge carriers as their lifetime is prolonged in the presence of the modulator augmenting their diffusion length. We present the incident photon-to-electron conversion efficiency (IPCE) spectrum of the best SN-containing PSC in Fig. 4c. The integrated current density derived from the IPCE spectrum presented in Fig. $4 \mathrm{c}$ is $23.4 \mathrm{~mA} \mathrm{~cm}^{-2}$ in good agreement with the $J_{\mathrm{SC}}$ value obtained from the $J-V$ curves, excluding any 
a
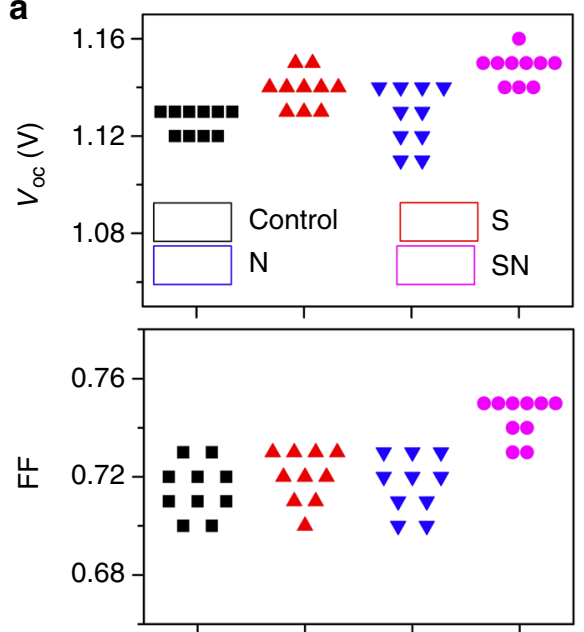

b

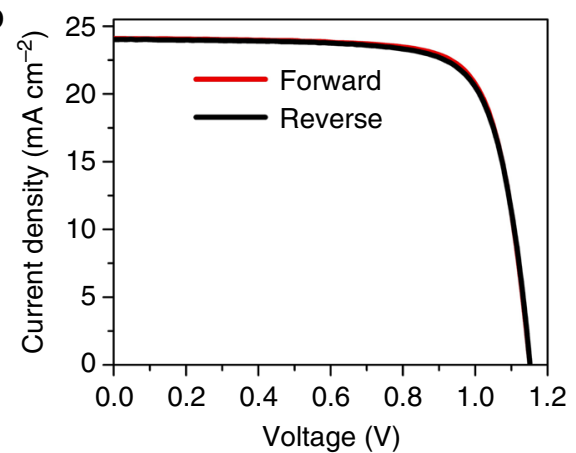

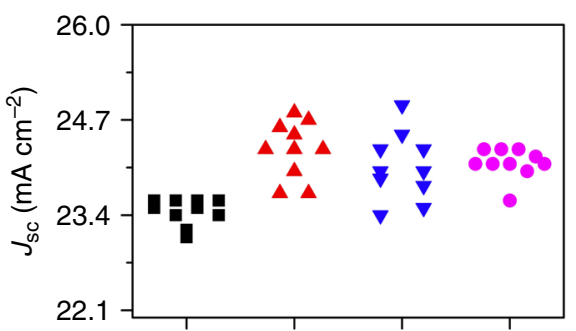

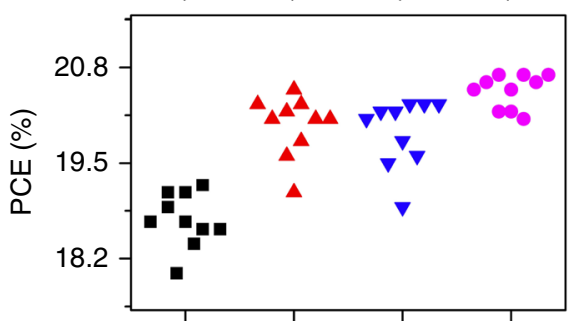

c

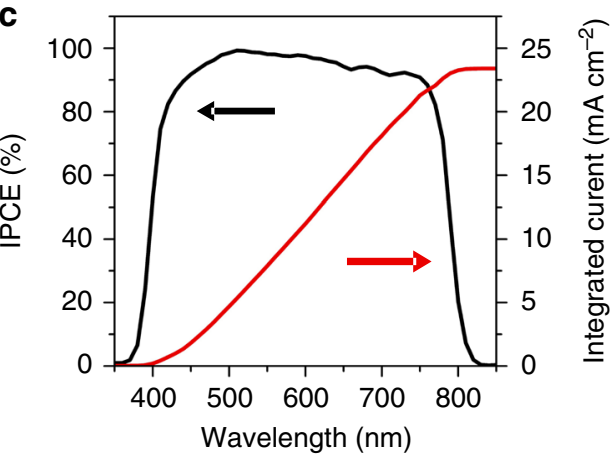

Fig. 4 Photovoltaic characterization. a PV metrics of perovskite solar cells with different modulators. All $J$ - $V$ curves recorded at a scanning rate of 50 mV s

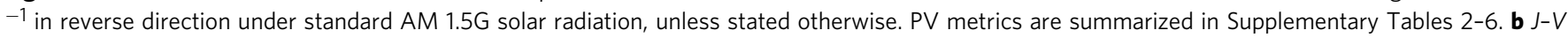
curves of the champion cell containing SN recorded in reverse (from $V_{\text {OC }}$ to $J_{S C}$ ) and forward (from $J_{S C}$ to $V_{\text {OC }}$ ) scanning directions under standard AM $1.5 \mathrm{G}$ solar radiation. The photovoltaic metrics derived from the two J-V curves are shown in the inset. c The corresponding IPCE spectrum (black curve) with the projected photocurrent (red curve) derived from integrating the IPCE over the standard AM 1.5G spectral emission

significant spectral mismatch between our simulator and the AM 1.5G solar source. This exceptional photovoltaic performance exemplifies the beneficial effect of molecular modulation on the structure and morphology of perovskite films.

Achieving operational stability through molecular modulation. The long-term photovoltaic performance of PSCs was scrutinized by probing the operational stability. Environmental degradation of the perovskite solar cells is mainly associated with the decomposition of the active perovskite layer due to corrosion by moisture invasion through the degraded top electrode, as well as the current leakage caused by the formation of hot spots in the bulk or at the interface ${ }^{37}$. For long-term stability toward environmental factors hydrophobicity of the films is an important criterion. In order to probe the hydrophobicity upon treatment with the molecular modulators we measured the contact angles of the corresponding films (for details refer to the Supplementary Figure 8 ). The angle of the hydrophobic chlorobenzene-based HTM solution droplet on the modulated perovskite film shows an enhanced wetting compared to the pristine perovskite samples, which indicates increased hydrophobicity of the perovskite surface, and, accordingly, improved compatibility of the perovskite layer with the HTM. This was particularly pronounced in case of the SN treatment. The operational stability was further evaluated by monitoring the effect of long term full sun light soaking at temperature between 55 and $60^{\circ} \mathrm{C}$ on the PCE of different PSCs in either Ar atmosphere or ambient air under continuous maximum power point tracking (MPP; Fig. 5). All the additives clearly enhance the operational stability of the PSCs. Remarkably, the SNcontaining perovskites maintained $98.1 \%$ of the initial PCE, whereas that of the pristine control decreased to $88.4 \%$ after 1000 $\mathrm{h}$ full solar light soaking of unsealed devices at $60^{\circ} \mathrm{C}$ under Ar gas (Fig. 5a). Even when submitted to light soaking over $500 \mathrm{~h}$ at their maximum power point in ambient air (Fig. 5b), the open PSCs containing SN suffered only minor degradation of $3.4 \%$.

The improvement of the perovskite stability upon treatment with the SN modulator may be associated with the suppression of morphological changes that occur during the aging process in the electronically active components of the PSC. The cross-sectional analysis of the evolution of the pristine and SN-treated perovskite films in completed PSC devices before and after aging under the aforementioned conditions reveal that in the as-prepared cells all the layers are compactly stacked, whereas the degraded samples feature morphological modifications (Fig. 5c, d). In the pristine case, appearance of voids can only be found at the interface of the perovskite layer of the cell aged in Ar atmosphere under 100\% light soaking. In the more extreme case of degrading under ambient air at $\sim 20 \%$ humidity, the pristine sample exhibits a more significant structural change, as obvious voids appear in the perovskite film which appears to be delaminated at the interfaces with $\mathrm{mp}-\mathrm{TiO}_{2}$ and HTM layers (Fig. 5c). The void-like structures represent inhomogeneities within the perovskite film that are likely to act as non-radiative recombination centers for photogenerated charge carriers during operation of the solar cell and 

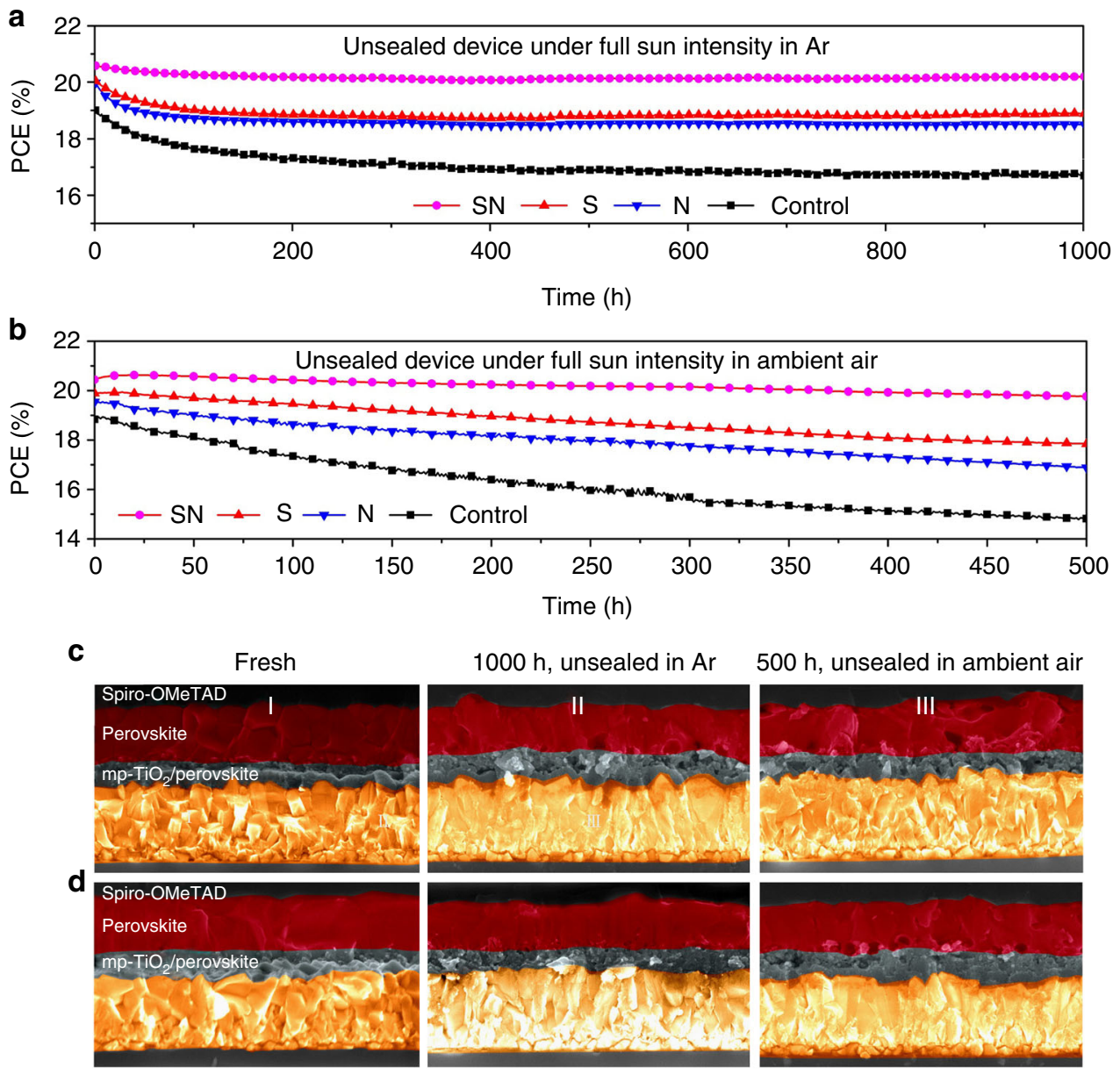

Fig. 5 Stability study. Evolution of the PCE over time measured by maximum power point tracking of unsealed PSCs of aperture area of $0.16 \mathrm{~cm}^{2}$ under light soaking with full solar intensity at temperature between 55 and $60^{\circ} \mathrm{C}$. Cells were kept under $\mathbf{a}$ Ar atmosphere and $\mathbf{b}$ ambient air at approximately $20 \%$ humidity. PV metrics are summarized in Supplementary Tables 7-10. Cross-sectional SEM images of the c pristine and $\mathbf{d}$ SN-modulated perovskite films in completed PSC devices before (I) and after aging under light soaking with full solar intensity at temperature between 55 and $60^{\circ} \mathrm{C}$ in $\mathrm{Ar}$ over $1000 \mathrm{~h}$ (II) and ambient air at $20 \%$ humidity over $500 \mathrm{~h}$ (III)

impair charge transport. On the other hand, the delamination effects at the interlayers are likely to impede the top-down charge transport and lead to regions that block the electric current flow, dramatically decreasing the PV performance of PSCs based on pristine perovskite film. Importantly, such inhomogeneities or delamination effects were not observed for the device containing the SN-modulated perovskite film after aging in Ar under light over $1000 \mathrm{~h}$, and much fewer voids were generated for the SNmodulated sample aged at $20 \%$ humidity over $500 \mathrm{~h}$ (Fig. 5d), which can be ascribed to the stabilization of the perovskite through interaction with the SN. These results provide evidence that the cell using the SN-modulated perovskite film exhibits superior long-term stability under light-soaking, highlighting the overall impact of this molecularly engineered organic modulator.

\section{Discussion}

In summary, we have demonstrated the effectiveness of multifunctional molecular modulation on the morphology and electronic properties of perovskite films of the most thermally stable $\mathrm{FA}_{0.9} \mathrm{Cs}_{0.1} \mathrm{PbI}_{3}$ formulation, and we elucidated the origin of the effects at the atomic level by employing solid state NMR spectroscopy. The molecularly engineered modulator, $\mathrm{SN}$, combines multiple functions by simultaneously passivating the surface defects, while displaying a structure-directing function through interaction with the perovskite that improves the electronic quality of the corresponding films. As a result, we achieve power conversion efficiency exceeding $20 \%$ for $1 \mathrm{~cm}^{2}$ active device area, which is accompanied by remarkable operational stability even in ambient air. This opens a new route for the realization of largescale perovskite solar cells of high efficiency and excellent operational stability. We are confident that the present prototype for multifunctional molecular modulators will stimulate other successful developments based on molecular design in the future.

\section{Methods}

Synthesis of organic materials. 3-(5-Mercapto- $1 H$-tetrazol-1-yl)benzenaminium iodide (SN) was synthesized by stirring equal molar ratios of 1-(3-aminophenyl)-5mercaptotetrazole and HI (57\% in water) at room temperature for $2 \mathrm{~h}$. The solvent was concentrated under vacuum, and the remaining solid was poured into $50 \mathrm{~mL}$ of diethyl ether and filtered. The precipitate was washed three times with diethyl ether and dried under vacuum to afford $\mathrm{SN}$ as a crystalline white product. NMR characterization: ${ }^{1} \mathrm{H}$ NMR $\left(400 \mathrm{MHz},\left(\mathrm{CD}_{3}\right)_{2} \mathrm{SO}\right): \delta=10.14(\mathrm{bs}, 4 \mathrm{H}), 7.54(\mathrm{~d}, J=2.2$ $\mathrm{Hz}, 1 \mathrm{H}), 7.50(\mathrm{~d}, J=5.3 \mathrm{~Hz}, 2 \mathrm{H}), 7.15(\mathrm{dd}, J=7.8,2.8 \mathrm{~Hz}, 1 \mathrm{H}) ;{ }^{13} \mathrm{C}$ NMR $(101$ $\left.\mathrm{MHz},\left(\mathrm{CD}_{3}\right)_{2} \mathrm{SO}\right): \delta=164.23,135.27,130.69,130.66,119.90,117.81,114.39 \mathrm{ppm}$.

Perovskite mechanosynthesis. Perovskite mechanosynthesis was performed based on the previously established procedures ${ }^{32,33}$. Starting materials were stored under inert argon atmosphere inside a glovebox. Perovskite powders were prepared by grinding the reactants in an electric ball mill (Retsch Ball Mill MM-200 using a grinding jar $(10 \mathrm{ml})$ and a ball $(\varnothing 10 \mathrm{~mm})$ for $30 \mathrm{~min}$ at $25 \mathrm{~Hz}$. The powders were packed into $3.2 \mathrm{~mm}$ zirconia rotors and annealed at $140^{\circ} \mathrm{C}$ for 10 min to reproduce the thin-film synthetic procedure and transferred into the NMR probe and the measurements were carried out under dry nitrogen atmosphere. We note that the 
perovskite $\alpha$ phase of mechanochemically prepared $\mathrm{FAPbI}_{3}$ is stable under these conditions (in dark, under dry nitrogen) for at least several days based on our previous experience $e^{32,33}$. The amounts of reagents taken into the synthesis were as follows: $\alpha-\mathrm{FAPbI}_{3}: 0.172 \mathrm{~g}$ formamidinium hydroiodide $(1.00 \mathrm{mmol})$ and $0.461 \mathrm{~g}$ $\mathrm{PbI}_{2}(1.00 \mathrm{mmol}) ; \alpha-\mathrm{FAPbI}_{3}$ doped with $4 \mathrm{~mol} \% \mathrm{SN}: 0.172 \mathrm{~g}$ formamidinium hydroiodide $(1.00 \mathrm{mmol}), 0.461 \mathrm{~g} \mathrm{PbI}_{2}(1.00 \mathrm{mmol}), 0.013 \mathrm{~g}(0.04 \mathrm{mmol}) ; 1: 1 \mathrm{~mol} /$ mol mixture of $\mathrm{SN}$ and $\mathrm{PbI}_{2}: 0.461 \mathrm{~g} \mathrm{PbI}_{2}(1.00 \mathrm{mmol}), 0.321 \mathrm{~g} \mathrm{SN}(1.00 \mathrm{mmol})$.

Solar cell preparation. A $30 \mathrm{~nm} \mathrm{TiO}_{2}$ compact blocking layer was deposited on the pre-cleaned FTO (NSG) by spray pyrolysis using $\mathrm{O}_{2}$ as the carrying gas at $450{ }^{\circ} \mathrm{C}$ from a solution of $0.6 \mathrm{~mL}$ titanium disisopropoxide bis(acetylacetonate) $(75 \%$ in isopropanol) and $0.4 \mathrm{~mL}$ bis(acetylacetonate) in $7 \mathrm{~mL}$ anhydrous isopropanol. A 150 $\mathrm{nm}$ mesoporous $\mathrm{TiO}_{2}$ was coated on the substrate by spin-coating with a speed of $5000 \mathrm{rpm}$ for $10 \mathrm{~s}$ with a ramp rate of $2000 \mathrm{rpm} \mathrm{s}^{-1}$, from a diluted $30 \mathrm{~nm} \mathrm{TiO}{ }_{2}$ particle paste (Dyesol $30 \mathrm{NR}-\mathrm{D}$ ) in ethanol with the weight ratio of $\mathrm{TiO}_{2}$ paste and ethanol of 6:1, and then the substrates were sintered at $500^{\circ} \mathrm{C}$ for $20 \mathrm{~min}$. The perovskite film was deposited by spin-coating onto the $\mathrm{TiO}_{2}$ substrate. The $\mathrm{FA}_{\mathrm{x}} \mathrm{Cs}_{1-\mathrm{x}} \mathrm{PbI}_{3}$ precursor solution was prepared in a glovebox from a $1.30 \mathrm{M} \mathrm{PbI}_{2}$ in the mixed solvent of DMF, GBL, and DMSO, with the molar ratios for GBL/DMF of 1.1:1 and $\mathrm{PbI}_{2} / \mathrm{DMSO}$ of 1:1.2. $\mathrm{HI}$ (57\% in water) was further added to the solution with volume ration of 5:100 with the precursor solution. For S, N, and SN modulators, we added different molecules into perovskite solution with the molar ratios of $2 \%$ vs $\mathrm{PbI}_{2}$. The spin-coating procedure was performed in ambient air by a consecutive twostep spin-coating process at first $1000 \mathrm{rpm}$ for $28 \mathrm{~s}$ with a ramp of $200 \mathrm{rpm} \mathrm{s}^{-1}$ and second $4000 \mathrm{rpm}$ for $18 \mathrm{~s}$ with a ramp of $2000 \mathrm{rpm} \mathrm{s}^{-1}$. For the deposition of the perovskite, vacuum-flash assisted solution processing (VASP) was used and the substrate was put into a chamber connected to a home-built vacuum-pumping instrument. The perovskite film was immediately exposed to low pressure maintained at $20 \mathrm{~Pa}$ for $8 \mathrm{~s}$ by opening the valve connecting the specimen chamber to the pump system, followed by full repressurization by releasing ambient air into the specimen chamber. Subsequently, the substrate was put on a hotplate and annealed at $100{ }^{\circ} \mathrm{C}$ for $60 \mathrm{~min}$ in ambient air at 20\% relative humidity. After the annealing process, we spincoated a passivation layer with $0.5 \mathrm{mg} / \mathrm{mL}$ of $\mathrm{S}, \mathrm{N}$, and $\mathrm{SN}$ modulators in isopropanol, followed by annealing at $70^{\circ} \mathrm{C}$ for $10 \mathrm{~min}$. After cooling down to room temperature, a hole-transporting material (spiro-OMeTAD) was deposited on top of the perovskite layer by spin-coating. The spin coating procedure was performed in a glovebox flushed with dry air, first at the rate of $1500 \mathrm{rpm}$ for $10 \mathrm{~s}$ with a ramp of $200 \mathrm{rpm} \mathrm{s}^{-1}$, followed by $4500 \mathrm{rpm}$ for $30 \mathrm{~s}$ with a ramp of $2000 \mathrm{rpm} \mathrm{s}^{-1}$. The spiro-OMeTAD solutions were prepared dissolving the spiro-OMeTAD in chlorobenzene at a concentration of $65 \mathrm{mM}(72.3 \mathrm{mg}$ in $1 \mathrm{~mL}$ of chlorobenzene), with the addition of $30 \mathrm{mM}$ lithium bis(trifluoromethanesulfonyl)imide $(17.5 \mu \mathrm{L}$ solution prepared by dissolving $520 \mathrm{mg}$ LiTFSI in $1 \mathrm{~mL}$ of acetonitrile) from a stock solution in acetonitrile and 200 $\mathrm{mM}$ of tert-butylpyridine $(28.8 \mu \mathrm{L})$. Finally, $80 \mathrm{~nm}$ of gold was deposited by thermal evaporation using a shadow mask to pattern the electrodes.

\section{Device characterization. Current-voltage characteristics were recorded under} ambient temperature and air conditions upon illumination by applying an external potential bias to the cell while recording the generated photocurrent with a digital source meter (Keithley Model 2400), without any device preconditioning. The light source was a 450-W Xenon lamp (Oriel) equipped with a SchottK113 Tempax sunlight filter (Praezisions Glas \& OptikGmbH) matching the emission spectrum of the lamp to the AM1.5 G standard. The exact light intensity was determined before each measurement using a calibrated Si reference diode equipped with an infrared cut-off filter (KG-3, Schott). All measurements were conducted using a non-reflective metal mask with an aperture area of $1.00 \mathrm{~cm}^{2}$ to cover part of the active area $(12 \mathrm{~mm} \times 12 \mathrm{~mm}=$ $1.44 \mathrm{~cm}^{2}$ ) of the device and avoid light scattering through the sides. The device area was determined by using the MICRO VUE sol 161 instrument. The stability was probed at the temperature of $55-60^{\circ} \mathrm{C}$, controlled by a Peltier element.

IPCE spectra were recorded under a constant white light of ca. $5 \mathrm{~mW} \mathrm{~cm}^{-2}$ supplied by an array of white light emitting diodes. The excitation beam from a 300-W Xenon lamp (ILC Technology) was focused through a Gemini-180 double monochromator (Jobin Yvon Ltd) and chopped at approximately $2 \mathrm{~Hz}$. The signal was recorded by means of a Model SR830 DSP Lock-In Amplifier (Stanford Research Systems).

Long term light soaking tests were conducted under a white light LED array with an intensity of $100 \mathrm{~mW} \mathrm{~cm}^{-2}$ simulating solar intensity and the cell temperature was maintained at temperature between 55 and $60^{\circ} \mathrm{C}$. The unsealed devices were maintained in an encapsulated box with a glass cover that was filled with argon or ambient air at $20 \%$ humidity. Data were collected automatically on the cells at an interval of $1 \mathrm{~h}$. Each measurement comprises a set of two $J-V$ curves, i.e. in the dark current and at $100 \mathrm{~mW} \mathrm{~cm}^{-2}$ light intensity between the measurement, the cells were maintained at the maximum power point using a MPPT algorithm. The mask of $0.16 \mathrm{~cm}^{2}$ aperture area was placed on top of the cell.

Material characterization. Solution NMR Spectra were recorded on a Bruker DRX 400 instrument operating at $400 \mathrm{MHz}$ at $298 \mathrm{~K} .{ }^{13} \mathrm{C}$ NMR spectra were recorded on a Bruker DRX 400 operating at $100 \mathrm{MHz}$. Multiplicities are reported as follows: bs (broad singlet), s (singlet), d (doublet), and $\mathrm{m}$ (multiplet). Chemical shifts $\delta(\mathrm{ppm})$ were referenced to the internal solvent signals.
Solid-state NMR measurements: variable-temperature solid-state MAS ${ }^{13} \mathrm{C}$ (125.8 MHz), ${ }^{15} \mathrm{~N}(50.7 \mathrm{MHz})$, and ${ }^{14} \mathrm{~N}(36.2 \mathrm{MHz})$ NMR spectra were acquired on a Bruker Avance III $11.7 \mathrm{~T}$ spectrometer equipped with a $3.2 \mathrm{~mm}$ low-temperature CPMAS probe. ${ }^{13} \mathrm{C}$ chemical shifts were referenced to solid adamantane at $298 \mathrm{~K}$ (CH: $\left.29.456 \mathrm{ppm}, \mathrm{CH}_{2}: 38.484 \mathrm{ppm}\right) .{ }^{15} \mathrm{~N}$ chemical shifts were referenced to $\mathrm{CH}_{3} \mathrm{NO}_{2}(0 \mathrm{ppm})$ using solid $\mathrm{NH}_{4} \mathrm{Cl}(-341.2 \mathrm{ppm})$ as a secondary reference at 298 K. ${ }^{14} \mathrm{~N}$ spectra were referenced to solid $\mathrm{NH}_{4} \mathrm{Cl}(0 \mathrm{ppm})$ at $298 \mathrm{~K}$. Longitudinal relaxation times $\left(T_{1}\right)$ were measured using a saturation-recovery sequence and were $1.6 \mathrm{~s}\left({ }^{1} \mathrm{H}\right.$ of SN, $\left.105 \mathrm{~K}\right), 1.6 \mathrm{~s}\left({ }^{1} \mathrm{H}\right.$ of $\left.\alpha-\mathrm{FAPbI}_{3}, 105 \mathrm{~K}\right), 0.2 \mathrm{~s}\left({ }^{14} \mathrm{~N}\right.$ of $\alpha-\mathrm{FAPbI}_{3}$, $295 \mathrm{~K}$ ). Low-temperature ${ }^{1} \mathrm{H}^{-13} \mathrm{C}$ and ${ }^{1} \mathrm{H}^{-15} \mathrm{~N}$ cross-polarization (CP) experiments used 3 and $4 \mathrm{~ms}$ optimized contact pulses, respectively, and $63 \mathrm{kHz}$ SPINAL- $64{ }^{1} \mathrm{H}$ decoupling.

X-ray diffraction (XRD) spectra were recorded on an X'Pert MPD PRO (PANanalytical) equipped with a ceramic tube delivering Ni-filtered $(\mathrm{CuK}=$ $1.54060 \AA$ ) radiation and a RTMS X'Celerator (PANalytical). The measurements were done in BRAGG-BRENTANO geometry from $2 \theta=8$ to 88 degree. The samples were mounted without modification and the automatic divergence slit (10 $\mathrm{mm}$ ) and beam mask $(10 \mathrm{~mm})$ were adjusted to the dimension of the films. A step size of 0.008 degree was chosen for an acquisition time of $270.57 \mathrm{~s}$ per degree. A baseline correction was used for all X-Ray powder diffractograms to compensate for the broad features arising from the FTO glass and anatase substrate.

Scanning electron microscope (SEM) images were recorded using a highresolution scanning electron microscope (FESEM, Merlin). An electron beam accelerated to $3 \mathrm{kV}$ was used with an in-lens detector. The spectra were measured with the perovskite infiltrated mesoscopic $\mathrm{TiO}_{2}$ films supported by FTO glass using a PerkinElmer Lambda 950 spectrophotometer.

Photoluminescence (PL) spectra were recorded by exciting the perovskite films deposited onto mesoporous $\mathrm{TiO}_{2}$ at $425 \mathrm{~nm}$ with a frequency-doubled picosecond Ti-Sapphire laser (pulse width $\sim 2 \mathrm{ps,} \mathrm{pump} \mathrm{fluence} \sim 0.1 \mu \mathrm{J} \mathrm{cm}{ }^{-2}$, spot diameter $\sim 0.1 \mathrm{~mm}$ ). The lase pulse impinged on the perovskite capping layer. The emission was recorded with a spectrometer (Horiba Jobin Yvon iHr320 and a CCD Sy).

Time-resolved photoluminescence (TRPL) experiments were performed on the same samples using the same laser as the PL measurements, and the signal was recorded using a Hamamatsu Streak Camera. The samples were excited from the perovskite side under ambient conditions. The signal rise time is $200 \mathrm{ps.}$

Cathodoluminescence (CL) spectra were acquired on the Attolight ROSA 4634 CL SEM operating at $5 \mathrm{kV}$ with the sample held at room temperature in a vacuum of $<10^{-7}$ Torr. To reduce sample charging, exposed surfaces of the glass substrate were coated with a conductive silver paint, and an electric circuit from the film surface to ground was made. Though the interaction volume at $5 \mathrm{kV}$ has roughly a diameter of $175 \mathrm{~nm}$, Monte Carlo simulations using the freeware program CASINO suggest that $50 \%$ of the CL signal emanates from a $25 \mathrm{~nm}$ region under the $5 \mathrm{~nm}$ SEM electron probe. The electron gun lens was set to $0.9 \mathrm{kV}$, and objective aperture size of $30 \mu \mathrm{m}$ was used to improve spatial resolution and limit the current to below $500 \mathrm{pA}$ to reduce electron beam heating and sample degradation. Hyperspectral maps were acquired with 128 pixel $\times 128$ pixel resolution, a pixel size of $50 \mathrm{~nm}$, and a pixel dwell (spectrum exposure) time of 100 $\mathrm{ms}$. The hyperspectral data were imported into MATLAB software for analysis. The average center emission wavelength for each sample type was determined, and false colored CL emission maps were reconstructed from deconvoluted CL intensity counts in the pixel spectra by subtracting the background and fitting the center CL emission peak with a Gaussian function.

Contact angle measurements were performed on a commercial Krüss drop shape analysis system at $298 \mathrm{~K}$. A droplet was added with a syringe. Images were taken using a high-resolution camera implemented in the instrument system. The contact angle was determined using the default instrument software.

DFT calculations. DFT calculations were conducted with the Gaussian 09 Rev. D suite of programs ${ }^{38,39}$, which was performed on Fidis computer cluster of EPF Lausanne. The geometry optimizations were performed at the B3LYP/6-31 G(d) level of theory and are shown in Supplementary Figure 1.

\section{Data availability}

The datasets generated during and/or analyzed during the current study are available from the first authors on reasonable request.

Received: 7 June 2018 Accepted: 22 September 2018 Published online: 26 October 2018

\section{References}

1. Kim, H. S. et al. Lead iodide perovskite sensitized all-solid-state submicron thin film mesoscopic solar cell with efficiency exceeding 9\%. Sci. Rep. 2, 591 (2012).

2. Lee, M. M., Teuscher, J., Miyasaka, T., Murakami, T. N. \& Snaith, H. J. Efficient hybrid solar cells based on meso-superstructured organometal halide perovskites. Science 338, 643-647 (2012). 
3. Jeon, N. J. et al. Compositional engineering of perovskite materials for highperformance solar cells. Nature 517, 476-480 (2015).

4. Bi, D. et al. Efficient luminescent solar cells based on tailored mixed-cation perovskites. Sci. Adv. 2, e1501170 (2016).

5. Bi, D. et al. Polymer-templated nucleation and crystal growth of perovskite films for solar cells with efficiency greater than $21 \%$. Nat. Energy 1, 16142 (2016).

6. Shin, S. S. et al. Colloidally prepared La-doped $\mathrm{BaSnO}_{3}$ electrodes for efficient, photostable perovskite solar cells. Science 356, 167 (2017).

7. Jeon, N. J. et al. A fluorene-terminated hole-transporting material for highly efficient and stable perovskite solar cells. Nat. Energy 3, 682-689 (2016).

8. Hoke, E. T. et al. Reversible photo-induced trap formation in mixed-halide hybrid perovskites for photovoltaics. Chem. Sci. 6, 613-617 (2015).

9. Conings, B. et al. Intrinsic thermal instability of methylammonium lead trihalide perovskite. Adv. Energy Mater. 5, 1500477 (2015).

10. Stranks, S. D. et al. Electron-hole diffusion lengths exceeding 1 micrometer in an organometal trihalide perovskite absorber. Science 342, 341-344 (2013).

11. Shi, D. et al. Low trap-state density and long carrier diffusion in organolead trihalide perovskite single crystals. Science 347, 519-522 (2015).

12. Yang, B. et al. Perovskite solar cells with near $100 \%$ internal quantum efficiency based on large single crystalline grains and vertical bulk heterojunctions. J. Am. Chem. Soc. 137, 9210-9213 (2015).

13. Liu, J. et al. Identification and mitigation of a critical interfacial instability in perovskite solar cells employing copper thiocyanate hole-transporter. $A d v$ Mater. Interfaces 3, 1600571 (2016).

14. Long, R., Liu, J. \& Prezhdo, O. V. Unravelling the effects of grain boundary and chemical doping on electron-hole recombination in $\mathrm{CH}_{3} \mathrm{NH}_{3} \mathrm{PbI}_{3}$ perovskite by time-domain atomistic simulation. J. Am. Chem. Soc. 138, 3884-3890 (2016).

15. Ye, S. et al. A breakthrough efficiency of $19.9 \%$ obtained in inverted perovskite solar cells by using an efficient trap state passivator $\mathrm{Cu}$ (thiourea)I. J. Am. Chem. Soc. 139, 7504-7512 (2017).

16. Koscher, B. A., Swabeck, J. K., Bronstein, N. D. \& Alivisatos, A. P. Essentially trap-free $\mathrm{CsPBBr}_{3}$ colloidal nanocrystals by postsynthetic thiocyanate surface treatment. J. Am. Chem. Soc. 139, 6566-6569 (2017).

17. Zheng, X. et al. Defect passivation in hybrid perovskite solar cells using quaternary ammonium halide anions and cations. Nat. Energy 2, 17102 (2017).

18. Cao, J. et al. Thiols as interfacial modifiers to enhance the performance and stability of perovskite solar cells. Nanoscale 7, 9443-9447 (2015).

19. Wang, Q., Dong, Q., Li, T., Gruverman, A. \& Huang, J. Thin insulating tunneling contacts for efficient and water-resistant perovskite solar cells. $A d v$. Mater. 28, 6734-6739 (2016).

20. Yun, J. H. et al. Synergistic enhancement and mechanism study of mechanical and moisture stability of perovskite solar cells introducing polyethylene-imine into the $\mathrm{CH}_{3} \mathrm{NH}_{3} \mathrm{PbI}_{3} / \mathrm{HTM}$ interface. J. Mater. Chem. A 3, 22176-22182 (2015).

21. Yang, S. et al. Functionalization of perovskite thin films with moisture-tolerant molecules. Nat. Energy 1, 15016 (2016).

22. Wen, X., Wu, J., Ye, M., Gao, D. \& Lin, C. Interface engineering via an insulating polymer for highly efficient and environmentally stable perovskite solar cells. Chem. Commun. 52, 11355-11358 (2016).

23. Zhang, J. et al. Bifunctional alkyl chain barriers for efficient perovskite solar cells. Chem. Commun. 51, 7047-7050 (2015).

24. Lee, J.-W. et al. Formamidinium and cesium hybridization for photo- and moisture-stable perovskite solar cell. Adv. Energy Mater. 5, 1501310 (2015).

25. $\mathrm{Yi}$, C. et al. Entropic stabilization of mixed A-cation $\mathrm{ABX}_{3}$ metal halide perovskites for high performance perovskite solar cells. Energy Environ. Sci. 9, 656-662 (2016).

26. McMeekin, D. P. et al. A mixed-cation lead mixed-halide perovskite absorber for tandem solar cells. Science 351, 151-155 (2016).

27. Yu, Y. et al. Improving the performance of formamidinium and cesium lead triiodide perovskite solar cells using lead thiocyanate additives. ChemSusChem. 9, 3288-3297 (2016).

28. Bush, K. A. et al. 23.6\%-efficient monolithic perovskite/silicon tandem solar cells with improved stability. Nat. Energy 2, 17009 (2017).

29. Li, X. et al. A vacuum flash-assisted solution process for high-efficiency largearea perovskite solar cells. Science 353, 58-62 (2016).

30. Auer, S. \& Frenkel, D. Suppression of crystal nucleation in polydisperse colloids due to increase of the surface free energy. Nature 413, 711-713 (2001).

31. Kondo, S., Ohsawa, H., Asada, H. \& Saito, T. Inherent excitonic luminescence in metal halide promising for potential applications in light-emitting devices. J. Appl. Phys. 107, 103526 (2010).

32. Kubicki, D. J. et al. Cation dynamics in mixed-cation $(\mathrm{MA})_{\mathrm{x}}(\mathrm{FA})_{1-\mathrm{x}} \mathrm{PbI}_{3}$ hybrid perovskites from solid-state NMR. J. Am. Chem. Soc. 139, 10055-10061 (2017).
33. Kubicki, D. J. et al. Phase segregation in Cs-, Rb- and K-doped mixed-cation $(\mathrm{MA})_{\mathrm{x}}(\mathrm{FA})_{1-\mathrm{x}} \mathrm{PbI}_{3}$ hybrid perovskites from solid-state NMR. J. Am. Chem. Soc. 139, 14173-14180 (2017)

34. Lobo, R. F., Zones, S. I. \& Davis, M. E. Structure-direction in zeolyte synthesis. J. Incl. Phenom. Mol. Recognit. Chem. 21, 47-78 (1995).

35. Lindblad, R. et al. Electronic structure of $\mathrm{TiO}_{2} / \mathrm{CH}_{3} \mathrm{NH}_{3} \mathrm{PbI}_{3}$ perovskite solar cell interfaces. J. Phys. Chem. Lett. 5, 648-653 (2014).

36. Huang, W., Manser, J. S., Kamat, P. V. \& Ptasinska, S. Evolution of chemical composition, morphology, and photovoltaic efficiency of $\mathrm{CH}_{3} \mathrm{NH}_{3} \mathrm{PbI}_{3}$ perovskite under ambient Conditions. Chem. Mater. 28, 303-311 (2016)

37. Domanski, K., Alharbi, E., Hagfeldt, A., Grätzel, M. \& Tress, W. Investigation of the impact of operation conditions on the degradation behaviour of perovskite solar cells. Nat. Energy 3, 61-67 (2018).

38. Foresman, J. B. \& Frisch, A. Exploring Chemistry with Electronic Structure Methods 2nd edn (Gaussian, Inc., Pittsburg, 1995).

39. Frisch, M. J. et al. Gaussian 09, Revision A.1 (Gaussian, Inc., Wallingford, CT, 2009).

\section{Acknowledgements}

D.B., J.V.M., N.P., M.G., and S.M.Z. are grateful to the Swiss National Science Foundation for financial support of the joint project IZLRZ2_164061 under the Scientific \& Technological Cooperation Program Switzerland-Russia and the European Union's Horizon 2020 research and innovation program (under grant agreement No. 687008, GOTSolar) and ERC Proof of concept grant (grant agreement No. 713681, PRINTSolar) X.L. acknowledges financial support from the Thousand Talent Program for Young Outstanding Scientists in China and the National Natural Science Foundation of China (21875081, 91733301). M.G. and S.M.Z. thank the King Abdulaziz City for Science and Technology (KACST) for financial support. D.J.K. and L.E acknowledge support from Swiss National Science Foundation Grant No. 200021_160112. Authors appreciate the support of Guido Rothenberger (EPFL) on devising the model for the kinetic analysis of time-resolved photoluminescence decay.

\section{Author contributions}

The manuscript was written by J.V.M., M.G., X.L., and D.B. through contributions of all authors. The idea of the study was conceived by M.G. while X.L. and D.B. introduced the ammonium substitution of the SN modulator. X.L. and D.B. also conducted the device fabrication and characterization. The molecular modulation was conceptualized by M.G. and J.V.M., who also performed the characterization of molecular modulators and contributed to elucidating the mode of action. D.J.K. and L.E. performed the solid-state NMR studies for elucidation of the mode of action, N.P. conducted the photoluminescence spectroscopy, J.L. scanning electron microscopy and X-ray diffraction, whereas T.L. and P.M. performed cathodoluminescence and XPS spectroscopy, respectively. S.M.Z. was involved in project coordination and M.G. supervised the study. All authors discussed the results and contributed to the study.

\section{Additional information}

Supplementary Information accompanies this paper at https://doi.org/10.1038/s41467018-06709-w.

Competing interests: The authors declare no competing interests.

Reprints and permission information is available online at http://npg.nature.com/ reprintsandpermissions/

Publisher's note: Springer Nature remains neutral with regard to jurisdictional claims in published maps and institutional affiliations.

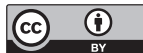

Open Access This article is licensed under a Creative Commons Attribution 4.0 International License, which permits use, sharing, adaptation, distribution and reproduction in any medium or format, as long as you give appropriate credit to the original author(s) and the source, provide a link to the Creative Commons license, and indicate if changes were made. The images or other third party material in this article are included in the article's Creative Commons license, unless indicated otherwise in a credit line to the material. If material is not included in the article's Creative Commons license and your intended use is not permitted by statutory regulation or exceeds the permitted use, you will need to obtain permission directly from the copyright holder. To view a copy of this license, visit http://creativecommons.org/ licenses/by/4.0/.

(C) The Author(s) 2018 